\title{
The Model of Makerspace Development Element and Performance Analysis Based on NVivo Classification
}

\author{
Yingyan Wang ${ }^{1,2}$ and Rui Zeng $\mathbb{D}^{1}$ \\ ${ }^{1}$ Yiwu Industrial and Commercial College, Yiwu 322000, China \\ ${ }^{2}$ Yiwu Innovation Research Institute, Yiwu 322000, China \\ Correspondence should be addressed to Rui Zeng; zengrui@ywicc.edu.cn
}

Received 19 July 2021; Revised 2 September 2021; Accepted 13 September 2021; Published 5 November 2021

Academic Editor: KunHong Liu

Copyright (c) 2021 Yingyan Wang and Rui Zeng. This is an open access article distributed under the Creative Commons Attribution License, which permits unrestricted use, distribution, and reproduction in any medium, provided the original work is properly cited.

\begin{abstract}
Makerspace is an innovation and entrepreneurship service platform. Its ultimate goal is to realize value cocreation among multiple subjects. The development of Makerspace and the realization of value are closely related to the Makerspace Development Policy. With the help of NVivo/ software, we analyzed 17 Makerspace Development Policies. Through the selection of samples, statistical analysis of word frequency, and coding analysis, the 7 core elements of entrepreneurial incentives, fee reductions and exemptions, employment support, entrepreneurial environment, talent support, financial support, and service optimization are summarized to form an empirical research survey of the development policy elements of the makerspace project. The author uses the game evolution method to analyze the mechanism of the internal relationship of innovation factors, builds a model of the development factors of the makerspace, selects 52 makerspace companies to conduct a questionnaire survey, using the model to conduct empirical research on the performance of existing policies, and finally proposes a model for makerspace development.
\end{abstract}

\section{Introduction}

Policy is the basic tool for governing the country, and public policy is the main means for the state and the government to realize their functions [1]. To comply with the new trend of mass innovation and entrepreneurship and further give play to its supporting role in the country's economic development, the State Council issued the Guiding Opinions on Developing Makerspace and Promoting Mass Innovation and Entrepreneurship in March 2015, which officially kicked off the prelude to the construction of makerspace. To further improve the service level of makerspace and promote the development of the new normal of China's economy, the State Council issued the Opinions of the State Council on Promoting High-Quality Development of Innovation and Entrepreneurship for an Upgrade Version in September 2018, which officially marked the start of a stage of high-quality construction of makerspace. Driven by China's innovationdriven development strategy decision-making, provincial governments have issued a series of policies to accelerate the development of makerspace and improve the quality of innovation and entrepreneurship services.

In recent years, the research of makerspace policy has gradually become a hot topic of government decisionmaking departments and academia. Scholars interpret and analyze the policy of makerspace from different perspectives. Poter from the perspective of industrial clusters combined with diamond theory carried out a simple analysis of the feasibility of the government to achieve agglomeration of elements. The main ways of action are as follows: (1) The government can influence the diamond system through subsidies, education, and financial market policies. The way in which the factors of production in the market then affect market demand affects the concentration of factors. (2) The government can affect the structural strategy of the enterprise and the form of competitors by affecting the industrial development environment. (3) The industrial form, external market conditions, and production factors in turn also 
affects policies [2]. Jacobs analyzed government behavior in industrial agglomeration under urban diversification and believed that the government can play a role through the allocation of capital and urban planning $[3,4]$. Baldwin and Fenge believed that government policy can affect industrial agglomeration through price index, but agglomeration does not depend entirely on price index but on government policy $[5,6]$. Lyons conducted an empirical analysis on the preferential policies implemented by the US state governments to promote industrial agglomeration and found that preferential policies represented by tax incentives and government subsidies have a positive impact on promoting regional enterprise clusters [7]. Cui built a policy analysis framework for makerspace from a three-dimensional perspective of policy tools, value attributes, and life cycle and pointed out that the policy system should pay more attention to the coordination and moderation of policies and suggestions to stimulate market vitality [8]. Xu analyzed 159 makerspace policy documents according to the research ideas of policy type-policy time-regional city by the quantitative research method from the perspective of policy tools [9]. Lei conducted a quantitative analysis on the policies for supporting the development of makerspace introduced by Shanghai by the content analysis method [10]. Wang studied the local policies of Shanghai makerspace from the perspective of dependent multilayer network, formed a supply framework of makerspace, and put forward the policy suggestions on the development of Shanghai makerspace [11]. In recent years, the international academia has recognized that the agglomeration of innovation elements within a certain spatial scope will produce agglomeration externalities and scale effects will promote innovation. More and more scholars at home and abroad have begun to pay attention to the agglomeration of innovative elements, the motivation of the agglomeration of innovative elements, and the relationship between policy guidance and the agglomeration of innovative elements. However, based on the existing literature, while the previous research provides rich experience and reference for this research, there are still certain shortcomings, mainly: the theory of agglomeration of innovative elements is based on the theory of industrial agglomeration, innovation network theory, growth pole theory, and production system. Based on theories and other theoretical foundations, the research on the agglomeration mechanism of innovative elements based on these theories usually ignores the role of government actions in guiding the agglomeration of innovative elements. Although some scholars have pointed out that the role of government intervention in the agglomeration economy has always been a weak link in the current theoretical research on factor agglomeration, few scholars have conducted in-depth research on it. In this paper, an analysis of 17 makerspace development policies of Zhejiang was conducted by NVivo, a qualitative analysis software. By continuously summarizing, 7 core concepts were finally summarized. Through the game evolution method to analyze the mechanism of the internal relationship of innovation factors and build a model of the development factors of the crowd-creation space and through the empirical research on policy performance, it is found that the balanced distribution of policy attention is not enough, and the government's support for talent policy and service effectiveness is weak.

\section{Selection and Statistical Analysis of the Policy Texts}

The selected makerspace development policy texts of Zhejiang were all derived from public data from the official websites of Zhejiang Provincial People's Government, vip. chinalawinfo.com, collection, release, and interpretation platform for mass innovation and entrepreneurship policy and other departments. To ensure that the policy sample selection was representative, comprehensive, and accurate, we determined the sample selection principles: first, the relevant policies are searched with "makerspace" and "innovation and entrepreneurship" as the key words; second, the time is selected from March 2015 when the Guiding Opinions of the General Office of the State Council on Developing Makerspace and Promoting Mass Innovation and Entrepreneurship was released to December 2019 when the makerspace policy was issued by Zhejiang; third, the policy by Zhejiang Provincial Government and various functional departments is formulated; and fourth, laws and regulations, planning, programs, opinions, methods, notices, announcements, and so on were selected as the policy documents, excluding informal decision-making documents such as approvals, leaders' speeches, and work reports. According to the above principles, 17 makerspace development policies of Zhejiang were finally selected, and the policy documents are shown in Table 1.

\section{Construction and Analysis of the Makerspace Development Element Model}

3.1. Statistical Analysis of the Policy Texts by Word Frequency. First, the statistical analysis of policy documents was conducted using the "word frequency" function of Nvivol1 (see Figure 1). The overview of makerspace development policies can be intuitively displayed through the word cloud map. Among them, "enterprise," "development," "innovation," “construction," “service," “industry," "technology," "entrepreneurship," and other keywords were in large font size; that is, they were high-frequency words, which showed that innovation and entrepreneurship, enterprise development, science and technology innovation, makerspace construction, service innovation were the key contents of the government in formulating the development policy of makerspace, and they embodied the main contents of makerspace development and involved different stages of innovation and entrepreneurship and related elements. The "enterprise" included small and microenterprises, high-tech enterprises, e-commerce enterprises, and other types of enterprise as well as all aspects of financial support for enterprises, so it was a high-frequency word in the policy text. The "development" was a high-frequency word in the policy text, indicating that the makerspace policy focused on promoting the development of enterprises, industrial development, talent development, and so on. The "innovation," including 
TABle 1: The makerspace development policy documents of Zhejiang.

\begin{tabular}{|c|c|c|}
\hline No. & Title & Issuing no. \\
\hline 1 & $\begin{array}{l}\text { Reply of the General Office of Zhejiang Provincial People's Government on the Pilot Plan of Science and } \\
\text { Technology System Reform of Hangzhou High-Tech Industrial Development Zone (Binjiang) }\end{array}$ & ZZBH[2015] No. 81 \\
\hline 2 & $\begin{array}{c}\text { Notice of Zhejiang Provincial People's Government on Printing and Issuing the "Internet +" Action Plan of } \\
\text { Zhejiang Province }\end{array}$ & ZZF[2016] No. 2 \\
\hline 3 & $\begin{array}{c}\text { Notice of Zhejiang Provincial People's Government on Printing and Issuing the "Made in China 2025" } \\
\text { Action Outline of Zhejiang Province }\end{array}$ & ZZF[2015] No. 51 \\
\hline 4 & $\begin{array}{c}\text { Notice of the General Office of Zhejiang Provincial People's Government on Printing and Issuing the "13th } \\
\text { Five-Year Plan" for Talent Development in Zhejiang Province }\end{array}$ & ZZBF[2016] No. 110 \\
\hline 5 & $\begin{array}{l}\text { Notice of the General Office of Zhejiang Provincial People's Government on Printing and Issuing the } \\
\text { Action Plan for Accelerating the Development of New Material Industry in Zhejiang Province (2019-2022) }\end{array}$ & ZZBF[2019] No. 22 \\
\hline 6 & $\begin{array}{l}\text { Implementation Opinions of the General Office of Zhejiang Provincial People's Government on } \\
\text { Developing the "Young Eagle Action" and Cultivating Hidden Champion Enterprises }\end{array}$ & ZZBF[2019] No. 28 \\
\hline 7 & $\begin{array}{l}\text { Implementation Opinions of Zhejiang Provincial People's Government on Vigorously Developing } \\
\text { E-commerce and Accelerating the Cultivation of New Economic Power }\end{array}$ & ZZF[2015] No. 49 \\
\hline 8 & $\begin{array}{l}\text { Notice of Zhejiang Provincial People's Government on Printing and Issuing the Outline of the 13th } \\
\text { Five-Year Plan for the National Economic and Social Development of Zhejiang Province }\end{array}$ & ZZF[2016] No. 8 \\
\hline 9 & $\begin{array}{l}\text { Opinions of the General Office of Zhejiang Provincial People's Government on Promoting the } \\
\text { Construction of Science and Technology Innovation Corridor of West Hangzhou }\end{array}$ & ZZBF[2016] No. 81 \\
\hline 10 & $\begin{array}{c}\text { Notice of the General Office of Zhejiang Provincial People's Government on Printing and Issuing the "13th } \\
\text { Five-Year Plan" for Major Construction Projects in Zhejiang Province }\end{array}$ & ZZBF[2016] No. 88 \\
\hline 11 & $\begin{array}{c}\text { Opinions of Zhejiang Provincial Department of Culture on Accelerating the Cultural Construction of } \\
\text { Characteristic Towns }\end{array}$ & ZWF[2016] No. 7 \\
\hline 12 & $\begin{array}{c}\text { Notice of the General Office of Zhejiang Provincial People's Government on Printing and Issuing the "13th } \\
\text { Five-Year Plan" for Service Industry Development of Zhejiang Province }\end{array}$ & ZZBF[2016] No. 102 \\
\hline 13 & $\begin{array}{l}\text { Notice of the General Office of Zhejiang Provincial People's Government on Printing and Issuing the Policy } \\
\text { of Burden Alleviation and Cost Reduction for Enterprises in Zhejiang Province (the First Batch in 2019) }\end{array}$ & ZZBF[2019] No. 25 \\
\hline 14 & $\begin{array}{c}\text { Notice of Zhejiang Provincial People's Government on Printing and Issuing the Implementation Plan for } \\
\text { Promoting the Development of Big Data in Zhejiang Province }\end{array}$ & ZZF[2016] No. 6 \\
\hline 15 & $\begin{array}{c}\text { Notice of the General Office of Zhejiang Provincial People's Government on Printing and Issuing the "13th } \\
\text { Five-Year Plan" for Development Plan of Advertising Industry in Zhejiang Province }\end{array}$ & ZGSG[2016] No. 6 \\
\hline 16 & $\begin{array}{l}\text { Opinions of the General Office of Zhejiang Provincial People's Government on Promoting the Innovative } \\
\text { Development of Small and Microenterprises }\end{array}$ & ZZBF[2018] No. 59 \\
\hline 17 & $\begin{array}{c}\text { Opinions of Zhejiang Provincial People's Government on Comprehensively Accelerating Scientific and } \\
\text { Technological Innovation and Promoting High-Quality Development }\end{array}$ & ZZBF[2018] No. 43 \\
\hline
\end{tabular}

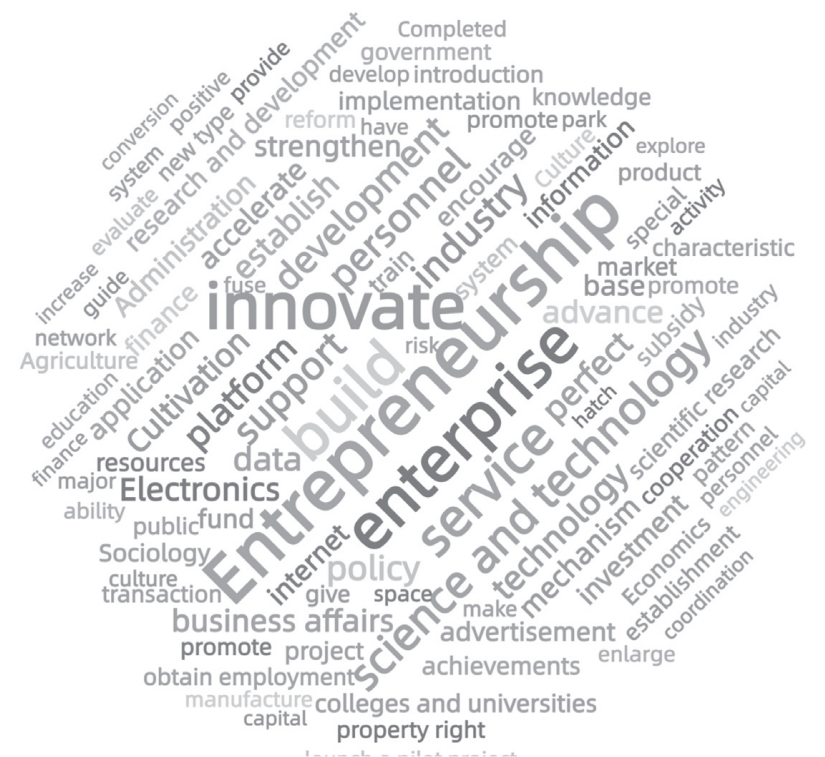

Figure 1: Word cloud map.

innovation and entrepreneurship, scientific and technological innovation, and service innovation, was the essence of makerspace development, so it was a high-frequency word in the policy text. The "service" appeared 1,124 times in the policy text, indicating that Zhejiang pays attention to innovation and entrepreneurship services. The "science and 
technology" appeared 957 times in the policy text, indicating that scientific and technological innovation and high-tech talents play an important role in the development of makerspace, and the services of competent departments at all levels in scientific and technological innovation, talent training, and talent introduction are extremely important. The cultivation of innovation and entrepreneurial talents and the development of makerspace have always been the focus of economically developed cities, and strengthening service construction is an important way to improve the service quality of makerspace.

Although the word frequency statistic has an intuitive effect, it can only roughly reflect the policy trend. To accurately judge the policy trend, we need to use the "node" function to conduct an in-depth coding analysis of the policy text.

\subsection{Data Encoding Analysis and Model Construction}

3.2.1. Open Encoding: Acquisition of the Direct Element of Makerspace Development Policy. To better analyze the policy texts, this paper open-encoded the policy documents according to the "localized" [12] principle of Grounded Theory. 30 makerspace development policy texts were imported into Nvivo11 for analysis and coding sentence by sentence. First, the policy documents were encoded into 686 free nodes, which were located at the bottom of the affiliation and were direct elements affecting the makerspace.

3.2.2. Axial Encoding: Construction of the Makerspace Development Element Model. Then, through in-depth analysis according to the relationship between the principal and the subordinate, the 686 free nodes were summarized and formed into 34 second-level nodes. All the contents of the policy texts were encoded as much as possible. The 34 second-level nodes were further summarized and formed 7 first-level nodes: "entrepreneurial incentive," "fee reduction," "employment support," "entrepreneurial environment," "talent support," "financial support," and "service optimization" (see Table 2). So far, after the analysis and node encoding of the 30 collected policy documents, the nodes at all levels of the makerspace development policies of Zhejiang were obtained. Based on the theory of innovation elements [13], the model of makerspace development element was constructed (Figure 2).

3.2.3. Analysis of the Basic Elements of Makerspace Development Policy. The basic idea of evolutionary game is that in a game group, the two parties of the game continue to engage in repeated game activities. Evolutionary game theory is a dynamic game process. The equilibrium point of both parties is experience. When the game process tends to be stable, $t$ will be more realistic in describing the evolution of the decisions of the two parties in the game and the evolution of the system. The basic concept of evolutionary game theory is evolutionary stability strategy, which provides the possibility for evolutionary game theory to study the game process of game groups from the perspective of bounded rationality.
The evolutionary stability strategy reflects the relatively stable situation formed in the dynamic game process. The specific process is to first select some individuals to participate in the game by random selection under a large population. The game strategies of these selected individuals have been specified in advance. After completion, the strategy of some individuals in the group participating in the game has changed; that is, another strategy set beforehand is selected. If the strategy chosen by these individuals does not cause the original strategy of the rest of the individuals to change, then the original strategy has produced a relatively different strategy. With high payouts, individuals who choose mutation strategies will either choose the original strategy to adapt to survival under external pressure or be excluded by the group. Evolutionary game strategy is a stable state in which a population resists the invasion of mutation strategy. Under the incentive of the government's guiding strategy, the main body of innovation factors chooses whether to enter the crowdcreation space to participate in innovation activities. This can be regarded as a dynamic game process. It has become the optimal strategy for most of the subjects of innovation. At this time, the government's guiding strategy will play a role in guiding the concentration of innovation. Evolutionary game theory and copying dynamic equations can vividly describe the frequency and frequency of a certain strategy used in a group. This provides theoretical and methodological enlightenment for us to study whether government strategies can be adopted by most innovative elements. It provides a theoretical basis for our understanding of the driving mechanism of the government to guide the agglomeration of innovative elements.

The node value of parent node element of makerspace development policy was 277 (see Table 2). From the reference number of the second-level nodes of policy support, we can see that the financial support had the most nodes, 90, which showed that there were many government support methods. The most important method was financial support, which can support industries and departments, such as financial investment and financial subsidies. The second is employment support. By introducing employment security measures and special subsidies for temporary employment, we can reduce the burden on entrepreneurs. The third was entrepreneurial incentive including various policies established by the government such as innovation incubation funds, entrepreneurial incentive mechanism, and risk compensation, which can improve the operation, management ability, and incubation ability of makerspace. The last was talent support, which was mentioned by only 10 policy documents.

\section{Analysis of the Internal Mechanism of Elements for the Government to Guide the Entrepreneurs into the Makerspace}

Through the solution to the evolutionary stability strategy $[14,15]$ between the government and the entrepreneurs, the internal mechanism of elements for the government to guide the entrepreneurs into the makerspace was analyzed. 
TABLE 2: Reference points of the elements of makerspace development policy of Zhejiang.

\begin{tabular}{|c|c|c|c|}
\hline Policy & Element classification & Material source & Reference point \\
\hline \multirow{7}{*}{${ }^{*}$ Makerspace development policy of Zhejiang (267) } & Entrepreneurial incentive & 16 & 40 \\
\hline & Fee reduction & 13 & 20 \\
\hline & Employment support & 15 & 64 \\
\hline & Entrepreneurial environment & 16 & 26 \\
\hline & Talent support & 10 & 11 \\
\hline & Financial support & 14 & 90 \\
\hline & Service optimization & 11 & 16 \\
\hline
\end{tabular}

* means the makerspace development policies of Zhejiang came from 17 makerspace development policy documents issued by Zhejiang from 2015 to 2020.

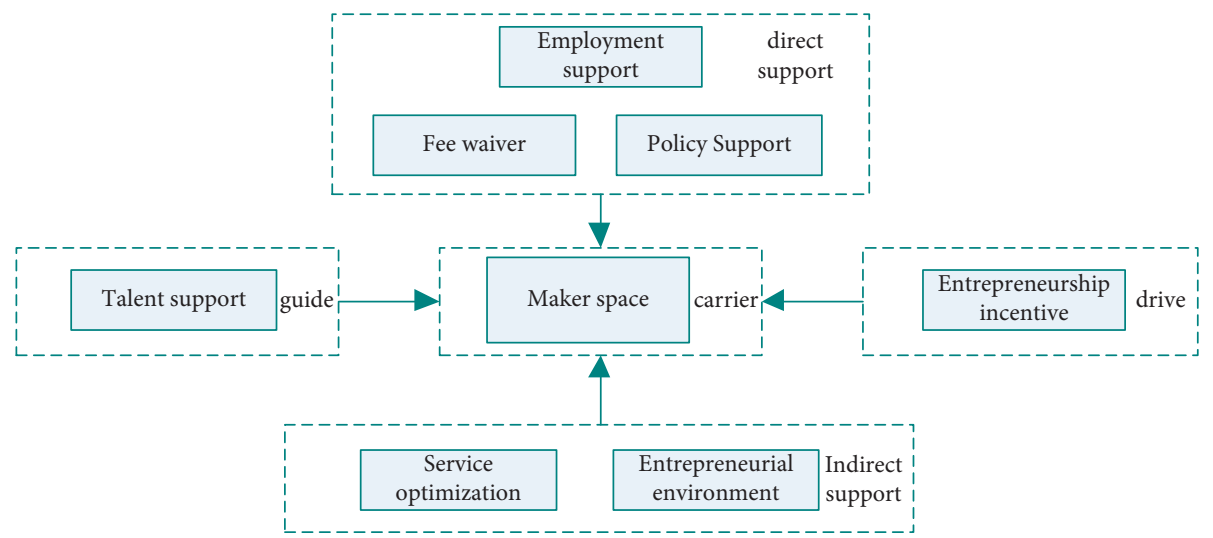

Figure 2: The model of makerspace development element.

\subsection{Establishment of the Payoff Matrix between the Government and the Entrepreneurs}

\subsubsection{Basic Assumptions and Parameters of the Game}

Assumption 1. Without considering the impact of other external environments, the participants of the game system are composed of two subjects: the government and the maker, and each subject is a bounded rational "economic man." Make mistakes and choose to adjust your strategy until you make the best decision.

Assumption 2 (opportunity cost of revenue (B) (that is, the basic salary of the current position) [16] and expected entrepreneurial revenue $\left(E X_{1}\right)$ ). One of the important reasons [17] why individuals give up their current work to start a business is that they can earn higher revenue than their basic wage $(B)$. Suppose the total revenue realized after the success of the business was $I$ and the tax rate was $\alpha$, but the premise of the implementation of $I$ was the entrepreneurial success. Suppose the probability $(C)$ of entrepreneurial success was a function of the richness and quality of services provided by the makerspace for the entrepreneurs, i.e., $C=D f(R, U)$. $D$ was the policy effect, which was a function of government subsidies, i.e., $D=D_{0} h\left(F_{z}\right), h\left(F_{z}\right)>0 . D_{0}$ was the initial status value. Thus, $C=D_{0} h\left(F_{z}\right), f(R, U)$. To sum up, $E X_{1}=a P I=a I D_{0} h\left(F_{z}\right)$.

Assumption 3 (entrepreneurial investment $(S)$ ). Starting a business requires not only energy but also a large amount of basic funds (such as office space costs, industrial and commercial administrative expenses, water-electricity-
Internet charges, and infrastructure purchase fees), as well as part of the entrepreneurial service charges that entrepreneurs enjoy in the makerspace. Here, we regarded all the entrepreneurial investment in the early stage of the business as the entrepreneurial investment $(S)$.

Assumption 4 (entrepreneurial policy incentives $\left(F_{c}\right)$ and opportunityc cost of capital $\left(S_{j 1}\right)$ ). Entrepreneurs invest the funds $(S)$ obtained through various channels into the startup while abandoning the possible revenue from these funds invested in other areas. Suppose the basic return rate in the capital market was $\theta$ and the capital gains tax was $\eta$. If these funds were invested into the capital market, the revenue was as follows: $S_{j 1}=(1+\theta)(1-\eta) S$.

Assumption 5 (Tax $(T))$. Entrepreneurial success will bring $\operatorname{tax}(T)$ to the government [18]. $T$ included the tax paid by the startup $\left(T_{1}=\phi a C I\right)$ and the tax paid by the makerspace $\left(T_{2}=\varphi b C I\right)$. To sum up, $T=(\phi a+\varphi b) C I$.

Assumption 6 (entrepreneurial effect $(Z)$, incentive derivative cost $\left(S_{y}\right)$, time value $(H)$, entrepreneurial policy incentives $\left.\left(F=F_{c}+F_{z}\right)\right)$. It included the entrepreneurial policy incentives for the entrepreneurs and the entrepreneurial policy incentives for the makerspace [19].

4.1.2. Construction of Evolutionary Game Revenue Payment Matrix. Suppose the probability that a maker enters the makerspace to participate in innovation and 
entrepreneurship is $C_{1}$, the probability that a maker does not enter the makerspace is $1-C_{1}$, the probability that the government chooses to support it is $C_{2}$, and the probability that it does not support is $1-C_{2}$. Based on the above model assumptions and parameter settings, the payment matrix of the evolutionary game model between the government and entrepreneurs is shown in Table 3.

\subsection{The Construction and Analysis of the Expectation Function of Both Sides of the Game between Government and Entrepreneurs}

4.2.1. Building of the Revenue Expectation Function. According to the above analysis, the return expectation function of the entrepreneurs and the government was constructed. Among them,

(1) The return expectation function of the entrepreneurs was as follows:

$$
\begin{aligned}
Q_{\text {Enter }} & =C_{2}\left[(1-\phi) a C I+F_{c}\right]+\left(1-C_{2}\right)(1-\phi) a C I=C_{2} F_{c}+(1-\phi) a C I, \\
Q_{N-\text { Enter }} & =C_{2}[B+(1+\theta)(1-\eta) S]+\left(1-C_{2}\right)[B+(1+\theta)(1-\eta) S]=B+(1+\theta)(1-\eta) S, \\
Q_{E} & =C_{1} Q_{\text {Enter }}+\left(1-C_{1}\right) Q_{N-\text { Enter. }}
\end{aligned}
$$

(2) The return expectation function of the government was as follows:

$$
\begin{aligned}
Q_{\text {INSPIRE }} & =C_{1}\left(T+Z-F-S_{y}+H\right)+\left(1-C_{1}\right)\left[\phi B+\eta(1+\theta) S-S_{y}\right], \\
Q_{N-\text { INSPIRE }} & =C_{1}(T+Z-H)+\left(1-C_{1}\right)[\phi B+\eta(1+\theta) S], \\
Q_{G} & =C_{2} Q_{\text {INSPIRE }}+\left(1-C_{2}\right) Q_{N-\text { INSPIRE }} .
\end{aligned}
$$

4.3. Solution to the Evolutionary Stability Strategy Based on Replication Dynamic Equation
(1) The replicated dynamic equation of the entrepreneurs was as follows:

$$
\begin{aligned}
M\left(C_{1}\right) & =\frac{d C_{1}}{d}=C_{1}\left(Q_{\mathrm{ENTER}}-Q_{E}\right)=C_{1}\left(1-C_{1}\right)\left\{\left[C_{2} F_{c}+(1-\phi) a C I\right]-[B+(1+\theta)(1-\eta) S]\right\} \\
M^{\prime}\left(C_{1}\right) & =\left(1-2 C_{1}\right)\left\{\left[C_{2} F_{c}+(1-\phi) a C I\right]-[B+(1+\eta)(1-\theta) S]\right\} .
\end{aligned}
$$

Making $M^{\prime}\left(C_{1}\right)=\left(d C_{1} / d\right)=0$, we obtained $C_{1}^{*}=$ $0, C_{1}^{*}=1$, and $C_{2}^{*}=((B+(1+\theta)(1-\eta) S-(1-\phi)$ $\left.a C I) /\left(F_{c}\right)\right)$.

Judging from the stability theorem of the replicated dynamic differential equation and the evolutionary stability strategy, when $M\left(C_{1}\right)=0, M^{\prime}\left(C_{1}\right)<0, P^{*}$ was the evolutionary stability strategy.

Discussion. If $C_{2}=((B+(1+\theta)(1-\eta) S-(1-\phi)$ $\left.a C I) /\left(F_{c}\right)\right)$, then $M\left(C_{1}\right)=0, M^{\prime}\left(C_{1}\right)=0$; that is, all $y$-axis levels were stationary; when the government incentives reached $C_{2}=((B+(1+\theta)(1-\eta) S-$ $\left.(1-\phi) a C I) /\left(F_{c}\right)\right)$, the possibility of entrepreneurs staying in the makerspace was all stable.

If $C_{2}>\left((B+(1+\theta)(1-\eta) S-(1-\phi) a C I) /\left(F_{c}\right)\right)$, for $\quad C_{1}^{*}=0$ and $C_{1}^{*}=1, \quad M^{\prime}(0)>0$ and $M^{\prime}(1)<0$. Now, $P_{1}^{*}=1$ was the unique evolutionary stability strategy; when the government incentives reached to a certain extent and continued to increase, it was the best choice for entrepreneurs to move in the makerspace.

If $C_{2}<\left((B+(1+\theta)(1-\eta) S-(1-\phi) a C I) /\left(F_{c}\right)\right)$, for $C_{1}^{*}=0$ and $C_{1}^{*}=1, \quad M^{\prime}(0)<0$ and $M^{\prime}(1)>0$. Now, $P_{1}^{*}=0$ was the unique evolutionary stability strategy; when the government incentives were weak enough and continued to weaken, the possibility of entrepreneurs staying in the makerspace would gradually reduce. At this time, it was the best choice for entrepreneurs not to start a business. The relationship between the intensity of government incentives and the possibility of capital flowing into the crowd-creation space to participate in innovation and entrepreneurship is shown in Figure 3.

(2) The replicated dynamic equation of the government was as follows: 
TABLE 3: The payoff function matrix of the entrepreneurs and the government under different strategies.

\begin{tabular}{lcr}
\hline \multirow{2}{*}{ Government policy } & \multicolumn{2}{c}{ Entrepreneur } \\
& Entry $C_{1}$ & $K_{E}=B+(1+\theta)(1-\eta) S$ \\
$C_{2}$ & $K_{E}=(1-\phi) a C I+F_{c}$ & $K_{G}=\phi B+\eta(1+\theta) S-S_{y}$ \\
\hline \multirow{2}{*}{$1-C_{2}$} & $K_{G}=T+Z-F-S_{y}+H$ & $K_{E}=B+(1+\theta)(1-\eta) S$ \\
& $K_{E}=(1-\phi) a C I$ & $K_{G}=\phi B+\eta(1+\theta) S$ \\
\hline
\end{tabular}
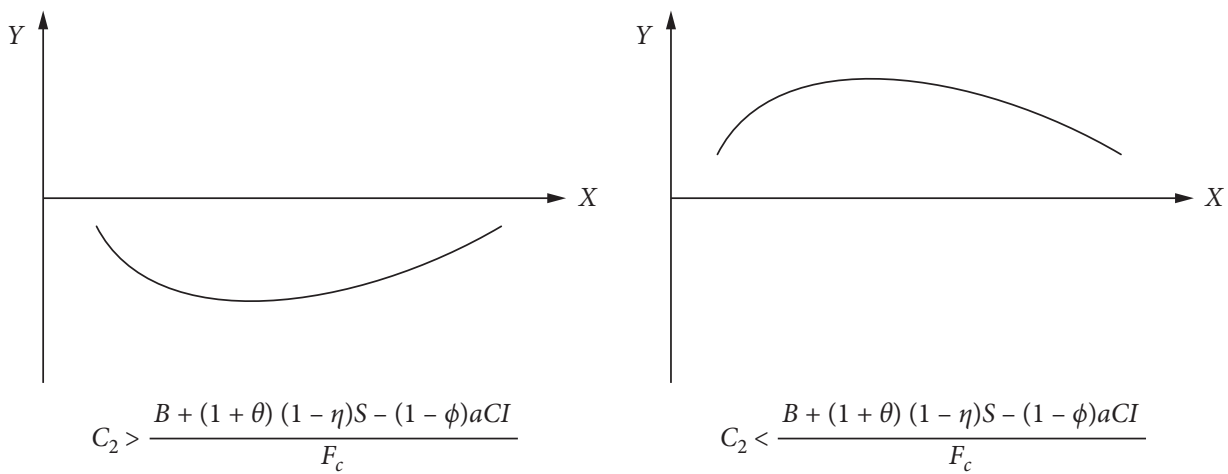

FIgURE 3: The replicated dynamic equation phase diagram for the possibility of entrepreneurs staying in the makerspace.

$$
\begin{gathered}
M\left(C_{2}\right)=\frac{d C_{2}}{d}=C_{2}\left(Q_{\text {INSPIRE }}-Q_{G}\right)=C_{2}\left(1-C_{2}\right)\left[C_{1}(2 T-F)-S_{y}\right], \\
M^{\prime}\left(C_{2}\right)=\left(1-2 C_{2}\right)\left[C_{1}(2 T-F)-S_{y}\right] .
\end{gathered}
$$

Making $\quad M\left(C_{2}\right)=\left(d C_{2} / d\right)=0$, we obtained $C_{2}^{*}=0, C_{2}^{*}=1$, and $C_{1}^{*}=\left(\left(S_{y}\right) /(2 T-F)\right)$.

Judging from the stability theorem of the replicated dynamic differential equation and the evolutionary stability strategy, when $M\left(C_{2}\right)=0$ and $M^{\prime}\left(C_{2}\right)<0, C^{*}$ was the evolutionary stability strategy.

Discussion. When $C_{1}=\left(S_{y} /(2 T-F)\right)$, then $M\left(C_{2}\right)=0$ and $M^{\prime}\left(C_{2}\right)=0$; that is, all $y$-axis levels were stationary; when the government incentives reached $C_{1}=\left(S_{y} /(2 T-F)\right)$, the government incentives were all stable.

If $C_{1}>\left(S_{y} /(2 T-F)\right)$, for $C_{2}^{*}=0$ and $C_{2}^{*}=1$, $M(0)>0$ and $M^{\prime}(1)<0$. Now, $C_{2}^{*}=0$ was the unique evolutionary stability strategy; when the possibility of entrepreneurs staying in the makerspace was strong enough and continued to increase, the government incentives would increase. At this time, it was the best choice for the government to increase incentives.

If $C_{1}=\left(S_{y} /(2 T-F)\right), \quad$ for $\quad C_{2}^{*}=0$ and $C_{2}^{*}=1$, $M(0)>0$ and $M^{\prime}(1)<0$. Now, $C_{2}^{*}=0$ was the unique evolutionary stability strategy; when the possibility of entrepreneurs staying in the makerspace was weak enough and continued to decrease, the government incentives would decrease. At this time, it was the best choice for the government to decrease incentives.
The dynamic trend and stability of the government incentives are shown in Figure 4.

4.4. Analysis of the Equilibrium Solution of Game. Based on the above analysis, the replicated dynamic relationship between the government and the entrepreneurs was constructed, which was represented by a two-dimensional plane coordinate, as shown in Figure 5.

In Figure 5, $O(0,0)$ and $B(1,1)$ were evolutionary stability strategies. $O(0,0)$ meant that entrepreneurs did not move in the makerspace, and the government did not take financial support measures. $B(1,1)$ meant that entrepreneurs actively moved in the makerspace to start businesses, and the government took vigorous financial support measures. In the upper right area of Figure 5, the actions of the both sides converged to $B(1,1)$, where both sides achieved a Pareto equilibrium [20]. In other words, there was no better point (except $B(1,1)$ ) in the above plane area which can make at least one side become better without making the existing situation worse.

In the lower left area of Figure 5, the actions of the both sides converged to $O(0,0)$, where the both sides achieved a Pareto equilibrium. In other words, there was no worse point (except $O(0,0))$ in the above plane area which can make at least one side become worse without making the existing situation better. In other areas of Figure 5, the convergence direction of the actions of the both sides would be uncertain. 

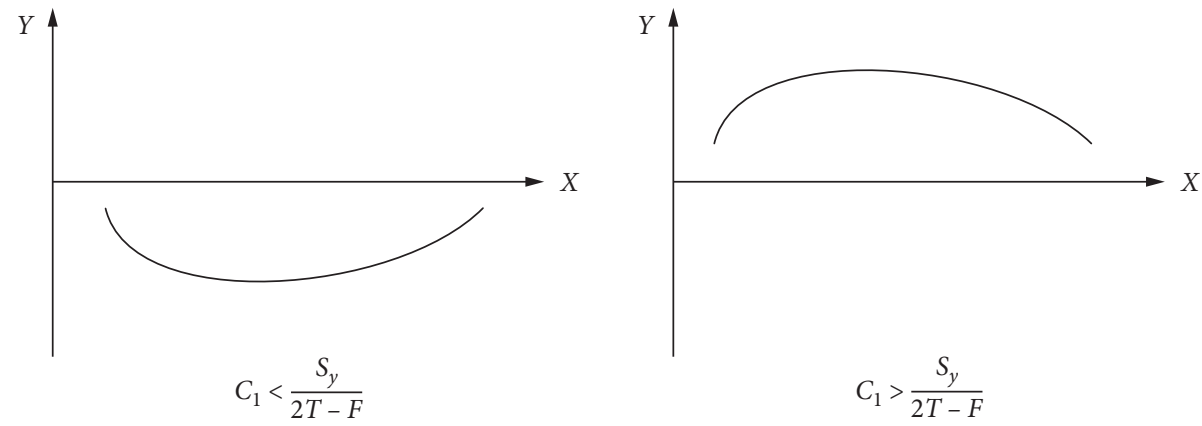

Figure 4: The replicated dynamic phase diagram of the government incentives.

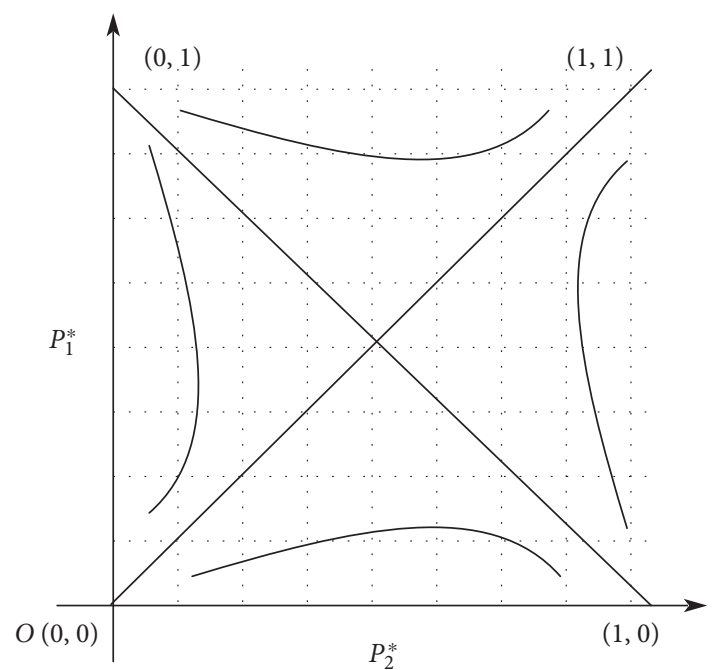

Figure 5: The schematic diagram of the replicated dynamics and stability of the both sides.

Through further analysis, if the system was made to converge to the optimal Pareto equilibrium point $B(1,1)$ with high probability, the equilibrium point of the both sides should appear in the upper right area of Figure 5. Now, the following conditions should be met: $C_{1}>\left(S_{y} /(2 T-F)\right)$ and $C_{2}>\left((B+(1+\theta)(1-\eta) S-(1-\phi) a C I) /\left(F_{c}\right)\right)$. Based on this, we obtained the following.

In $\quad C_{2}=\left((B+(1+\theta)(1-\eta) S-(1-\phi) a C I) /\left(F_{c}\right)\right)$, there was a positive relationship between the basic wage $(B)$, capital market value $(r)$, entrepreneurial investment $(S)$, individual income tax rate $(\phi)$, and $C_{2}^{*}$; there was a reverse relationship between the capital gains tax $(\eta)$, the proportion of income distribution of innovation achievements $(a)$, the success rate of entrepreneurship $(C)$, the total income of innovation achievements $(I)$, and $C_{2}^{*}$. Through the above analysis, we got $C=D f(R, U)=D_{0} g\left(F_{z}\right) f(R, U)$. Therefore, it was further concluded that there was also a reverse relationship between the quantity $R$ and quality $U$ of the entrepreneurial service types provided by the makerspace, the financial subsidies provided by the government to the makerspace, and $C_{2}^{*}$.

In $C_{1}^{*}=\left(S_{y} /(2 T-F)\right)$, there was a positive relationship between the government incentives $F=F_{c}+F_{z}\left(F_{c}\right.$ means government incentives for the entrepreneurs and $F_{z}$ means government incentives for the makerspace), incentive derivative cost $\left(S_{y}\right)$, and $C_{1}^{*}$; there was a reverse relationship between the time value $(M)$ and $C_{1}^{*}$.

\section{Empirical Analysis}

\subsection{Data Acquisition and Validity Analysis}

(1) Data Acquisition. Same as the data acquired in the index system, the data on the implementation of policy tools also came from 52 makerspaces of Zhejiang, but they were acquired through the satisfaction survey of the policies formulated. The policies were tested by Liken five-level scale [21], with the policies not enjoyed by the makerspace being 0 point. The policies enjoyed by the makerspace were measured by satisfaction, which was divided into five dimensions: very satisfied, satisfied, general, unsatisfied, and very unsatisfied, with the scores of 5-1 point, respectively. Although 52 makerspaces were surveyed, 38 questionnaires were recovered, including 7 invalid questionnaires and 31 valid questionnaires.

(2) Reliability and Validity Test. The reliability of the support policy scale was analyzed using SPSS, a statistical analysis software, to test its internal consistency, namely, to measure whether each policy reflected the effect that the policy should be expressed.

Reliability index, also known as reliability coefficient, is a quantitative method to test reliability with Cronbach's $\phi$. Cronbach's $\alpha$ of the policy scale was 0.865 , indicating that the internal reliability of the policy scale was good.

Validity is to measure whether the comprehensive evaluation system can accurately reflect the evaluation purpose and requirements and refers to the correctness of the characteristics measured by measuring tools. The higher the validity, the higher the correctness of the characteristics measured by measuring tools. The author classifies the policies according to the dimensions of employment support policies, entrepreneurship incentive policies, talent support policies, and financial support policies and designs the items of the scale according to the policies, as shown in Table 4. By deleting and modifying some items of the scale, we get the optimized efficiency scale, as shown in Table 5. 
TABLE 4: Government policy elements scale of makerspace.

\begin{tabular}{lc}
\hline Variable dimensions & Measurement questions \\
\hline & (Aa1) Introduce employment protection measures \\
Employment support policies & (Aa2) Temporary special subsidy for employment \\
& (Aa3) Provide employment guidance services
\end{tabular}

(Ab1) Award based on the crowd-creation space recognized by the city, province, country, and other different levels

Entrepreneurial incentive policies

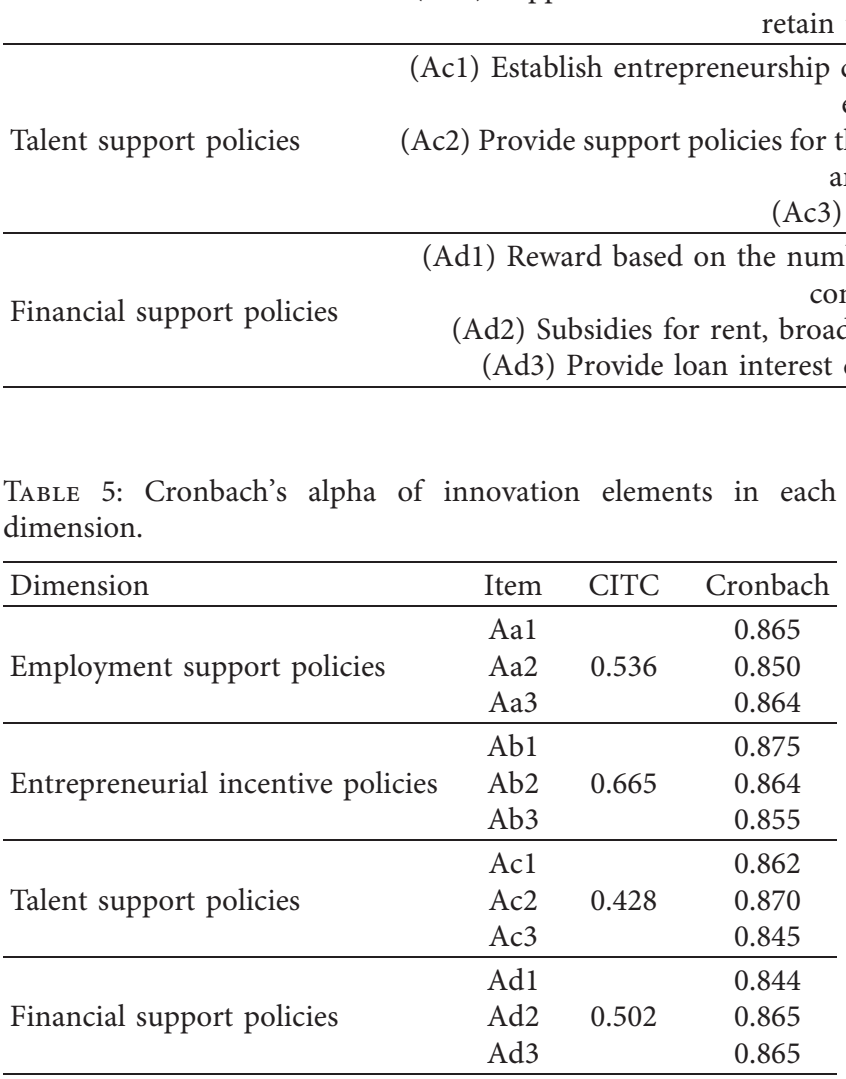

5.2. Construction of the Policy Effect Measurement Model. In this study, the general multiple regression analysis model was constructed based on the statistical analysis of data through survey questionnaires. The policy category was $n ; y_{1}, y_{2}, y_{3}$, and $y_{4}$ were the explanatory variables, which represented employment support policies, entrepreneurial incentive policies, talent support policies, and financial support policies, respectively; $h$ was the intercept item, which was a constant; $t$ was the number of statistical dimensions of the model data; $Z K_{0}$ was the innovation support ability of makerspace; $Z K_{1}$ was the maker attraction ability of makerspace; $Z K_{2}$ was the entrepreneurial resource guidance ability of makerspace; and $Z K_{3}$ was the entrepreneurial output ability of makerspace; the model was as follows:

$$
Z K_{t}=a_{i} y_{i}+\cdots+a_{n} y_{n}+h .
$$

5.3. Empirical Results. The SPSS was used to bring the processed raw data into the model for regression, as shown in Table 6.
The regression results of $Z K_{0}$ showed that employment support policies, entrepreneurial incentive policies, and financial support policies had a positive effect on the $Z K_{0}$, while talent support policies had a negative effect on $Z K_{0}$. The regression results of $Z K_{1}$ showed that employment support policies, entrepreneurial incentive policies, and financial support policies had a positive effect on $Z K_{1}$, while talent support policies had a negative effect on $Z K_{1}$. The effect of policy on $Z K_{1}$ was consistent with that on $Z K_{0}$. The difference was that talent support policies had an insignificant negative effect on $Z K_{1}$ and entrepreneurial incentive policies had the strongest positive effect on $Z K_{1}$, followed by financial support policies. The regression results of $Z K_{2}$ showed that only financial support policies had a positive effect on $Z K_{2}$. The regression results of $Z K_{3}$ showed that employment support policies and entrepreneurial incentive policies had a positive effect on $Z K_{3}$, while talent support policies and financial support policies had a negative effect on $Z K_{3}$.

\section{Problem Analysis and Policy Improvement Suggestions}

6.1. Insufficient Balanced Distribution of Policy Attention and Weak Government Support for Talent Support Policies and Service Support Effectiveness. Judging from the material source and reference point of the parent node of Zhejiang, there was a large gap between the times of nodes mentioned in the policy documents, and the government focused on financial support, entrepreneurial environment, entrepreneurial incentives, and employment support. As for the agglomeration ability of entrepreneurs, the influence coefficient of employment support policies, entrepreneurial incentive policies, and financial support policies was positive, which suggested that the three types of policies broke through the policy trigger point (equilibrium point) in the process of implementation and realized the agglomeration of entrepreneurs in the makerspace. The influence coefficient of 
TABLE 6: Empirical results.

\begin{tabular}{lcccc}
\hline & \multicolumn{2}{c}{ Policy performance } \\
& Innovation support ability & Attraction ability & Resource guidance ability & Output ability \\
\hline Employment support policies & 0.0578 & $-0.504^{* *}$ & $0.171^{*}$ & $0.148^{*}$ \\
Entrepreneurial incentive policies & $-0.239 *$ & $-0.139^{*}$ & 0.067 & $0.128^{*}$ \\
Talent support policies & $-0.277^{*}$ & $0.279^{*}$ & $-0.401^{*}$ & $-0.427^{* * *}$ \\
Financial support policies & $0.278^{*}$ & $-0.145^{*}$ & -0.022 & $0.08^{*}$ \\
\hline
\end{tabular}

Note. The figure in brackets is $t ;{ }^{*},{ }^{* *}$, and ${ }^{* * *}$ indicate significance at the significance level of $10 \%, 5 \%$, and $1 \%$, respectively.

the three types of policies in order from large to small was financial support policies > entrepreneurial incentive policies $>$ employment support policies. It can be seen that in the process of entrepreneurs to decide whether to enter the makerspace, the financial support policies were their first consideration, followed by the entrepreneurial incentive policies. Although the employment support policies broke through the policy trigger point (equilibrium point), the effect was not significant. The talent support policies were the opportunity element of the development of makerspace and the core element of innovation. The effect of talent service was the motivation goal of the development of makerspace, and the powerful talent policy was an important force to promote the development of makerspace. However, at present, Zhejiang does not pay enough attention to the makerspace policies in talent and ignores the support for opportunities and motivation goals when formulating policies. Therefore, the formulation of makerspace development policies must strengthen the emphasis on talent support policies and service results.

6.2. Policy Improvement Suggestions. The report to the 19th National Congress of the Communist Party of China calls for implementing a more active, more developed, and more effective talent policy to gather talents from all over the world and accelerate the building of a talent power. Zhejiang Provincial Talent Work Conference put forward to highlight the "best and brightest talents" guidance and to build the best province of talent ecology. Therefore, the implementation of accurate introduction of talents is imperative. The accurate introduction of talents is to introduce and manage talents to meet the needs of makerspace industry and ensure that everyone can become talented and everyone can show their talents. The state and local governments have also issued a series of policy documents on talent introduction and management, such as "Thousand Talents Program," "Hundred Talents Program," and "151 Talents." However, studies have shown that the local talent introduction policies have a high homogenization and the lack of differentiation, leading to the single talent introduction channel and the homogenization of talent [22]. Innovation drives development, and talent leads innovation. To gain influence for makerspace in the competition, the key is to accelerate the agglomeration of makerspace innovative talents. Therefore, we should pay attention to talent planning and make Zhejiang become the place of talent agglomeration by means of the talent introduction model and talent flow guarantee mechanism. First, the talent introduction model is innovated, and equal emphasis on talent introduction and talent cultivation is advocated. The traditional "government-led" and "capitalized" talent introduction model is reformed [23], and the talent introduction model of "combining government support and market mechanism" is established. In other words, the government plays a guiding and promoting role in the macroaspects such as the reward policy and guarantee policy of talent introduction. And the employers implement other microaspects such as talent introduction way, talent types, standards, treatment, scientific research, and entrepreneurial working environment in accordance with the market mechanism. According to the needs of industrial development, the employers should do a good job in top-level design and overall planning, clear the goal of talent introduction, attract talents as needed, and focus on the cultivation of makerspace talents. According to the needs of local economic development, the employers should formulate the talent cultivation mechanism and strengthen the follow-up cultivation of local talents and introduced talents so that the introduced talents can drive local talents, and they learn from each other, creating an environment for harmonious development.

In addition, attention is paid to both the introduction of talents at home and abroad and the guarantee mechanism of talent loss. By 2050, the total number of international immigrants will reach 405 million, with about $70 \%$ of skilled immigrants $[24,25]$. Attracting and retaining these talents are the source of impetus for the future development of makerspace. Therefore, talents are introduced according to the regional makerspace development practice and the talent policies are dynamically adjusted for different development stages of makerspace, to ensure the organic integration of talent development with makerspace and social and economic development as well as the precise docking of talent introduction with makerspace industry demand and to reduce the waste of resources and talent loss caused by blind introduction. Besides, pay close attention to the innovation and entrepreneurship work after the introduction of talents to make them adapt to the innovation and entrepreneurship atmosphere of makerspace as soon as possible, track, analyze, evaluate and feedback the innovation and entrepreneurial behavior and achievements so as to timely improve the talent management mechanism, adjust the talent strategy, and ensure the stable development of the talent team.

\section{Data Availability}

The data used to support the findings of this study are included within the article. 


\section{Conflicts of Interest}

The authors declare that there are no conflicts of interest regarding the publication of this paper.

\section{Acknowledgments}

The research presented in this paper was supported by Zhejiang Provincial Soft Science Research Plan Project of China "Research on the Driving Mechanism and Performance Evaluation of Policy Guiding Innovation Factors to Gather in Makerspace: An Empirical Study of Zhejiang" (grant no. 2019C35050).

\section{References}

[1] X. Z. Xu, "Construction of localization theory based on empirical empirical research- comment on research on localization of educational policy process in China," Research in Educational Development, vol. 37, no. 5, pp. 83-84, 2017.

[2] M. Porter, The Competitive Advantage of Nations, Free Press, New York, NY, USA, 1990.

[3] J. Jacobs, The Economy of Cities, Random House, New York, NY, USA, 1969.

[4] J. Jacobs, The Death and Life of Great American Cities, Random House, NewYork, NY, USA, 1961.

[5] R. Baldwin, R. Forslid, P. Martin, G. Ottaviano, F. R. Nicoud, and F. Robert-Nicoud, Economic Geography and Public Policy, Princeton University Press, Princeton, NJ, USA, 2003.

[6] R. Fenge, M. von Ehrlich, and M. Wrede, "Public input competition and agglomeration," Regional Science and Urban Economics, vol. 39, no. 5, pp. 621-631, 2009.

[7] T. S. Lyons, Economy Development: Strategies for State and Local Practice, International City/County Management Association (ICMA), Washington, DC, USA, 2010.

[8] X. M. Cui, "Text analysis of mass innovation space policy based on three-dimensional perspective," Science and Technology Management Research, vol. 37, no. 17, pp. 30-36, 2019.

[9] S. B. Xu, "Policy research on the development of mass maker space from the perspective of policy tools," China Science and Technology Forum, vol. 35, no. 6, pp. 29-39, 2019.

[10] L. H. Lei and T. M. Jia, "Research on maker-space policy system of Shanghai," Shanghai Economic Research, vol. 37, no. 3, pp. 34-41, 2017.

[11] H. H. Wang, Y. Li, L. J. Xiong, M. Du, and Q. Sun, "Local policy supply of mass innovation space from the perspective of interdependent multi-layer network: a case study of Shanghai," Research and Development Management, vol. 31, no. 6, pp. 13-23, 2019.

[12] J. M. Corbin and A. L. Strauss, Fundamentals of Qualitative Research: Procedures and Methods for Forming GroundedTheory, Chongqing University Press, Chongqing, China, 3rd edition, 2015.

[13] G. S. Chen, "A review of the theoretical model of the core factors of entrepreneurship," Advances in Domain, vol. 17, no. 12, 2007.

[14] Z. B. Li, S. Liu, and L. L. Liu, "Research on the value added path of incubating small and medium-sized enterprises by crowd maker space: experience from 69 crowd maker spaces in Tianjin," Science and Technology Progress and Countermeasures, vol. 35, no. 3, pp. 72-79, 2018.
[15] B. W. Zhou and Z. S. Zhang, "Crowd innovation culture: an urgent field to be studied," Management Modernization, vol. 4, 2017.

[16] F. Huang and L. Q. Liu, "Maker space culture with Chinese characteristics," Learning and Practice, vol. 8, 2017.

[17] L. Zhao and G. R. Chai, "Research on the development and evolution of enterprise and maker space innovation cooperation network," Studies in Science of Science, vol. 35, no. 2, 2017.

[18] Y. P. Li and W. Chen, "Research on the ecological network elements and capacity generation of maker-oriented platform organization,” Economic Management, vol. 6, 2017.

[19] People's Daily Online, "Comment on: avoid the homogeneity of the gen space supporting policies need to be born," 2015, http://scitech.people.com.cn/n/2015/1105/c1007-27782036. html.

[20] Y. S. Xi, “The allocation of local governments' attention in the construction of double first class: an analysis of NVIVO software based on 30 provincial policy text," Research on Education Development, vol. 37, no. 21, pp. 31-38, 2017.

[21] J. L. Yu and Q. C. Yao, "From data to evidence: research on the construction of government evidence-based decision-making mechanism in the era of big data," Chinese Administrative Management, vol. 27, no. 4, pp. 81-87, 2020.

[22] S. Wu, "Study on the homogeneity of China's overseas talent promotion policy from the perspective of governmental relations," Chinese Administration Management, vol. 21, no. 9, pp. 89-92, 2014.

[23] Y. Li and J. P. Zhang, "Introduction and management of highlevel talents in the "Double First-class" construction," Science and Technology of Chinese Universities, vol. 25, no. 12, 2019.

[24] J. Wu, "Strengthening the cornerstone of the modernization of national governance with talents," Guangming Daily, Amoxicillin, vol. 8, no. 7, 2019.

[25] J. Q. Chen, A. T. Xu, and J. C. Li, “The continuous distance measurement of crowd maker space agglomeration and its influencing factors," Business Economics and Management, vol. 39, no. 3, pp. 89-97, 2019. 